\title{
Trends in splenectomy in the Trent region 1972-85
}

\author{
I.W. Fellows, Sheila Hart and P.J. Toghill \\ University Hospital, Queen's Medical Centre, Nottingham NG7 2UH, UK.
}

\begin{abstract}
Summary: During the period 1972-85, 3712 splenectomies were performed in the Trent region giving a mean splenectomy rate of 5.8 per 100,000 population per year. Of these, $37.4 \%$ were incidental to other surgical operations and $23.4 \%$ were as a result of trauma. During this period there was a marked reduction in the splenectomy rate in children aged under 10 years for trauma and for haematological diseases. No such reduction was observed in older patients for these indications. Splenectomy for lymphoma fell progressively after 1977.
\end{abstract}

\section{Introduction}

Growing concern about the risk of postsplenectomy sepsis in adults is leading to a reappraisal of the needs for splenectomy and a trend towards conservation of splenic tissue. Whilst individual surgeons and hospitals in various parts of the world have published their own series of splenectomies, relatively little is known about general surgical trends in splenectomy in the United Kingdom. We report an analysis of splenectomies carried out in the Trent region during the period 1972 to 1985.

\section{Patients and methods}

The Trent region comprises a mixed urban and rural population of $4,600,000$ with a $\mathrm{M} / \mathrm{F}$ ratio of $0.97 / 1$. It contains three medical schools, Nottingham, Leicester and Sheffield and there are extensive accident and emergency and oncological services throughout the region. Figures for this analysis were obtained from the regional Hospital Activity Analysis (HAA) based at Sheffield using the International Classification of Disease.

\section{Results}

During the 14 year period a total of 3712 splenectomies were performed giving a mean splenectomy rate of 5.8 per 100,000 population per year and a $\mathrm{M} / \mathrm{F}$ ratio of $1.58 / 1$. The main groups are shown in Figure 1; $37.4 \%$ of these splenectomies were incidental to other surgical operations; $20.3 \%$ were

Correspondence: I.W. Fellows, D.M., M.R.C.P. Accepted: 27 October 1987

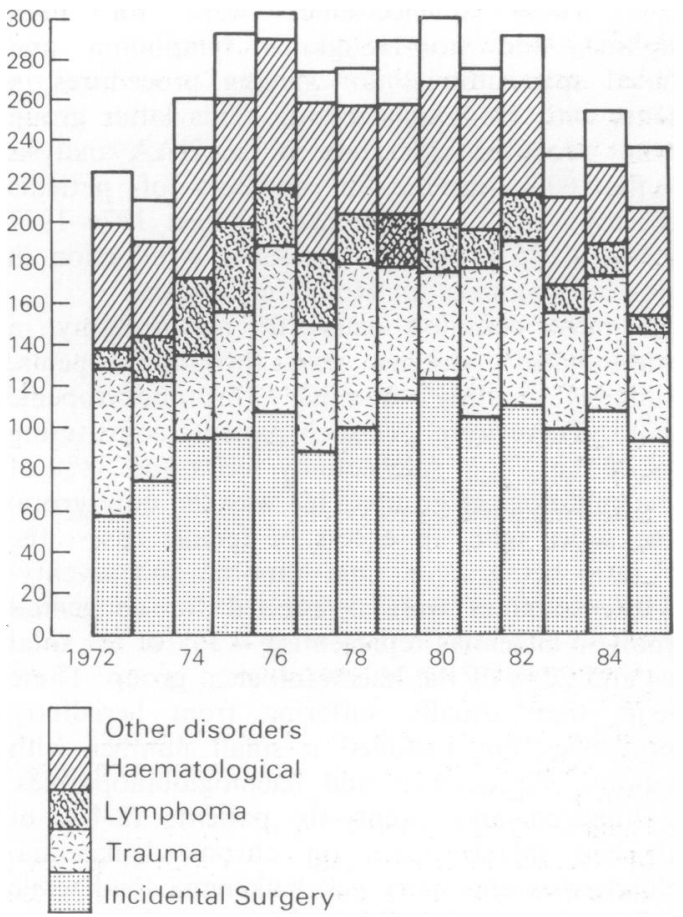

Figure 1 Reasons for splenectomy in the Trent Region 1972-85.

in relation to surgery for malignancies such as carcinoma of the stomach, colon, kidney and pancreas. The number of splenectomies performed as part of procedures for intra-abdominal carcinoma increased by $40 \%$ between the quinquennia 19721976 and 1981-1985. This increase was confined to

(C) The Fellowship of Postgraduate Medicine, 1988 
patients over 50 years old and was greatest in patients aged 70 to 79 years. In $17.1 \%$ of this series, the spleen was removed during operations for benign diseases such as peptic ulcer, diaphragmatic hernia and left nephrectomy.

Eight hundred and seventy-two splenectomies $(23.4 \%$ of the total) were for trauma usually in association with other bony or visceral injuries. A ratio of $\mathrm{M} / \mathrm{F}$ of $3.5 / 1$ presumably reflects the increased injury rate in males due to car and motor-cycle accidents together with industrial injuries. There was a $61 \%$ decrease in splenectomy rate for trauma in children aged 0-9 years between the quinquennia 1972-1976 and 1981-1985. This contrasted with the increase in splenectomies for trauma in young adults between these dates.

Three hundred and twenty-two splenectomies for lymphoma accounted for $8.7 \%$ of the total. Here there was an excess of males with a ratio $M / F$ of $1.75 / 1$. These splenectomies were for both Hodgkin's and non-Hodgkin's lymphoma and included splenectomies for staging procedures in patients with Hodgkin's disease. This latter group was not recorded separately in the HAA analysis but the $60 \%$ decline in numbers of patients splenectomized for lymphoma between 1974-1977 and 1982-1985 probably represents a reduction in staging laparotomies for Hodgkin's disease.

The most common cause for splenectomy in haematological patients was thrombocytopenia, presumably mainly immune thrombocytopenic purpura. There were 297 such patients constituting $8.0 \%$ of the whole splenectomy series and $38 \%$ of the haematological group. This was the only group in the series with an excess of female cases, the $\mathrm{M} / \mathrm{F}$ ratio being $1 / 1.8$. One hundred and seventyfive splenectomies were performed for congenital haemolytic anaemias representing $4.7 \%$ of the total series and $22 \%$ of the haematological group. These patients were usually suffering from hereditary spherocytosis but included a small number with congenital elliptocytosis and haemoglobinopathies. One hundred and twenty-six patients $(3.4 \%$ of total) had splenectomies for chronic leukaemia, myelosclerosis and hairy cell leukaemia (leukaemic reticulo-endotheliosis). Surprisingly small numbers of patients had splenectomies for acquired haemolytic anaemia $(1.0 \%$ of the whole series) but some patients may have been classified separately under the heading of hypersplenism. This heterogeneous and unsatisfactory category included unexplained splenomegaly, diagnostic splenectomies and Felty's syndrome and constituted $4.0 \%$ of the total. In the age group 0-9 years there was a $70 \%$ reduction in splenectomy rates for haematological reasons between the quinquennia 1972-1976 and 1981-1985. There was little change in other age groups.
Thirty-six patients (1\% of total) had splenectomies for chronic liver disease, mainly in relation to operations for relief of portal hypertension.

\section{Discussion}

It has been calculated that the mortality rate for sepsis in splenectomized adults is 540 times greater than in the general population ${ }^{1}$ although the risk after splenectomy for trauma may be less marked. ${ }^{2}$ Awareness of the problems of post-splenectomy sepsis has led physicians to reconsider the need for elective splenectomy in patients with lymphoma and haematological disease and has prompted surgeons to question the necessity for splenectomy in trauma and elective operations. Few figures are available about the size of the splenectomized population. Dickerman has estimated that 35,000 splenectomies take place in the USA each year. ${ }^{3}$ This gives a splenectomy rate of $15.2 / 100,000$ population per year, considerably in excess of the Trent figures of $5.8 / 100,000$ per year.

The commonest reason for splenectomy in the Trent series was an incidental procedure during major surgery. Whilst splenectomy may be mandatory in many operations for gastric, colonic and pancreatic malignancy, it is not always essential in routine operations in the splenic region, such as diaphragmatic hernia repair. Indeed, in the present series splenectomy was often necessary because of damage to the spleen during operations on organs distant from the left upper quadrant. The previously casual attitude of some surgeons to incidental splenectomy during other operations is now unjustified. In earlier splenectomy series, it is difficult to differentiate splenectomies performed for iatrogenic trauma from those performed deliberately to facilitate access or because of direct extension of tumour. Nevertheless, the figure for incidental splenectomy of $37.3 \%$ derived from the Trent figures is probably representative of most unselected series of splenectomies ${ }^{1,12-17}$ (Table I).

In the present series, $23.4 \%$ of all splenectomies were performed for trauma. Whilst splenic repair has been practised by some paediatric surgeons, general surgeons have been less enthusiastic about its adoption. ${ }^{4}$ This is reflected in the marked reduction in splenectomy rates for trauma in young children with a rise in numbers of young adults splenectomized for trauma during the period of this study. It is clear that this is a potential field in which splenic tissue could be conserved and in one study $85 \%$ of traumatized spleens were salvaged. ${ }^{5}$ Autotransplantation of splenic tissue in omental pouches may be effective, restoring splenic function. ${ }^{6}$ Several authors have suggested that postsplenectomy sepsis is minimal after splenectomy for 


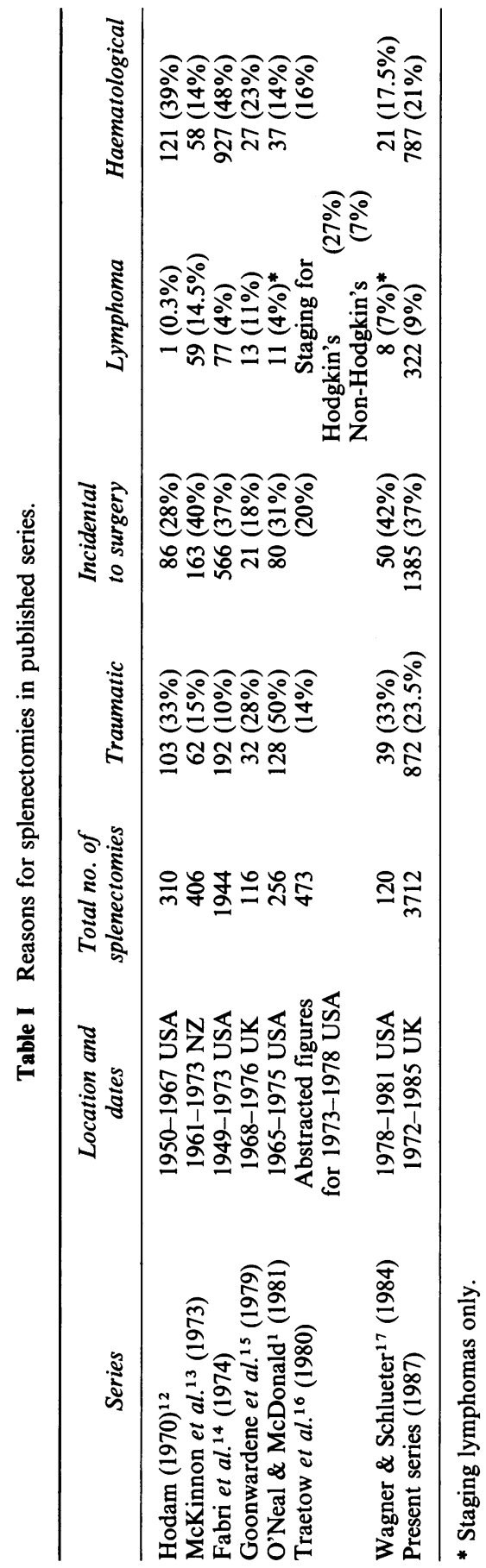

trauma $a^{7,8,9}$ and that this may be due to the concept of the 'born again' spleen where nodules of splenic tissue implant and grow in the peritoneal surface to restore immunological function. ${ }^{10}$ However, fatal septicaemia after splenectomy for trauma has been reported in the presence of ectopic splenic tissue. ${ }^{11}$

Splenectomy for lymphoma reached a peak during the period 1974-77 and declined subsequently. The increased numbers of splenectomies at that time probably reflected the enthusiasm of staging laparotomy and splenectomy in Hodgkin's disease. ${ }^{18}$ Indeed, during the period 1973-1979 staging laparotomy for Hodgkin's disease emerged as the most frequent indication for splenectomy in Ohio State University Hospital. ${ }^{16}$ With more sophisticated scanning techniques and improving knowledge of the management of Hodgkin's disease the need for surgical staging procedures has decreased. ${ }^{19}$

Except in young children the pattern of splenectomy for the primary haematological disorders appears to have altered little during the period under consideration with splenectomy for immune thrombocytopenic purpura and congenital haemolytic anaemia being the major indication.

The validity of these data depends upon the assiduity with which HAA coding clerks perform their function. Recent publications from other areas suggest that between $68 \%^{20}$ and $100 \%^{21}$ of splenectomies performed are coded as such by HAA units. In the present study attention has been drawn to trends of a considerable magnitude only. Furthermore, it seems unlikely that a marked reduction in splenectomy rates for trauma and for haematological diseases in children under 10 years old, with concomitant increases in older groups, could be explained by HAA coding errors.

What can be done to safe-guard the splenectomized population? Prophylactic long term antibiotics are effective in preventing post-splenectomy sepsis $^{22}$ and should be mandatory for at least 3 years after splenectomy. The efficacy of pneumococcal vaccines has been questioned ${ }^{23}$ and as yet there are no trials to demonstrate their value in preventing pneumococcal septicaemia after . splenectomy. Nevertheless the vaccines have offered some protection to patients with hyposplenism secondary to sickle cell anaemia. ${ }^{24}$ The need for such prophylactic measures could be diminished by a policy of splenic preservation. The present study suggests that while paediatric surgeons have adopted this practice, their adult counterparts continue to remove spleens unnecessarily.

\section{Acknowledgements}

We thank the Medical Statistical Department at the Sheffield Regional Hospital Board for their help in supplying the figures used in this analysis. 


\section{References}

1. O'Neal, B.J. \& McDonald, J.C. The risk of sepsis in the asplenic adult. Ann Surg 1981, 194: 775-778.

2. Dickerman, J.D. Traumatic asplenia in adults: a defined hazard? Arch Surg 1981, 116: 361-363.

3. Dickerman, J.D. Splenectomy and sepsis: A warning. Pediatrics 1979, 63: 938-939.

4. Mitchell, A. \& Morris, P.J. Surgery of the spleen. Clin Haematol 1983, 12: 565-590.

5. Pachter, H.L., Hofstetter, S.R. \& Spencer, F.C. Evolving concepts in splenic surgery. Ann Surg 1981, 194: 262-269.

6. Patel, J., Williams, J.S., Shmigel, B. \& Hinshaw, J.R. Preservation of splenic function by autotransplantation of traumatised spleen in man. Surgery 1980, 90: 683-688.

7. Pedersen, F.K. Post-splenectomy infections in Danish children splenectomised 1969-1978. Acta Paediatr Scand 1983, 72: 589-595.

8. Wahlby, L. \& Domellof, L. Splenectomy after blunt trauma: a retrospective study of 413 children. Acta Chir Scand 1981, 141: 131-135.

9. Chaikof, E.L. \& McCabe, C.J. Fatal overwhelming post-splenectomy infection. Am J Surg 1985, 149: 534-539.

10. Pearson, H.A., Johnson, D., Smith, K.A. \& Touloukian, R.J. The born-again spleen. Return of splenic function after splenectomy for trauma. $N$ Engl J Med 1978, 298: 1389-1392.

11. Rice, H.M. \& James, P.D. Ectopic splenic tissue failed to prevent fatal pneumococcal septicaemia after splenectomy for trauma. Lancet 1980, i: 565-566.

12. Hodam, R.P. The risk of splenectomy. Am J Surg 1970, 119: 709-713.

13. McKinnon, W.M.P., Snaders, H.S., Zamera, L.F. et al. Splenectomy: indications, results and complications in 406 patients. Am Surg 1973, 39: 72-74.
14. Fabri, P.J., Metz, E.N., Nick, M.V. \& Zollinger, R.H. A quarter century with splenectomy. Arch Surg 1974, 108: $569-575$.

15. Goonwardene, A., Bourke, J.B., Ferguson, R. \& Toghill, P.J. Splenectomy for undiagnosed splenomegaly. Br J Surg 1979, 66: 62-65.

16. Traetow, W.D., Fabri, P.J. \& Carey, L.C. Changing indications for splenectomy - thirty years experience. Arch Surg 1980, 115: 447-451.

17. Wagner, D.S. \& Schlueter, T.M. Splenectomy: indications, complications and mortality. Ohio State Med J 1984, 80: 610-613.

18. Worthy, T.S. Evaluation of diagnostic laparotomy and splenectomy in Hodgkin's disease. (Report No. 12). Clin Radiol 1981, 32: 523-536.

19. Larson, R.A. \& Ultmann, J.E. The strategic role of laparotomy in staging Hodgkin's disease. Cancer Treat Rep 1982, 66: 767-774.

20. Whates, P.D., Birzaalis, A.R. \& Irving, M. Accuracy of hospital activity analysis operation codes. $\mathrm{Br}$ Med J 1982, 284: 1857-1858.

21. Butts, M.S. \& Williams, D.R.R. Accuracy of hospital activity analysis data. Br Med J 1982, 285: 506-507.

22. Zarrabi, M.H. \& Rosner, F. Rarity of failure of penicillin prophylaxis to prevent post-splenectomy sepsis. Arch Intern Med 1986, 146: 1207-1208.

23. Simberkoff, M.A., Cross, A.P., Al-Ibrahim, M. et al. Efficacy of pneumococcal vaccine in high risk patients. N Engl J Med 1986, 315: 1318-1327.

24. Weintrub, P.S., Schiffman, G., Addiego, J.E. et al. Long term follow-up and booster immunization with polyvalent pneumococcal polysaccharide in patients with sickle cell anaemia. $J$ Pediatr 1984, 105: 261-263. 